\title{
Optimization of parameters of a modal active control in a beam of composite material
}

\author{
Camila Albertin Xavier da Silva ${ }^{l}$, Erik Taketa ${ }^{l}$, Edson Hideki Koroishi ${ }^{1,}{ }^{*}$, Fabian Andres \\ Lara-Molina ${ }^{l}$, and Albert Willian Faria ${ }^{2}$ \\ ${ }^{1}$ Federal University of Technology of Paraná - Campus Cornélio Procópio, Mechanical Engineering \\ Department, Avenue Alberto Carazzai, 1640, 86300-000, Cornélio Procópio, Paraná, Brazil. \\ ${ }^{2}$ Federal University of Triângulo Mineiro, ICTE, Civil Engineering Department, Avenue Dr. Randolfo \\ Borges Junior, 1250, Unit I, 38064-200, Uberaba, Minas Gerais, Brazil.
}

\begin{abstract}
The present work proposes the active vibration control in a beam of composite material, using electromagnetic actuators, in order to obtain a reduction in the response of the displacement of the system associated to a reduction in energy consumption. The control theory used was the linear quadratic regulator solved by linear matrix inequalities. The electromagnetic actuator was then linearized using a methodology similar to that used in magnetic bearings. The work also proposes to study the optimization of parameters applied in this active control, by means of the heuristic optimization methods. From numerical simulations, the system's response was obtained in the time domain that demonstrated the efficiency of the proposed technique in the active control of vibrations.
\end{abstract}

\section{Introduction}

Composite materials are widely used in industrial, medical and military areas [1], and in recent years the active vibration control in these structures has attracted the interest of researchers as limitations of weight, dimensions and positioning in some industrial applications.

In the context of these mechanical systems with optimum performance, this work proposes the use of the modal active vibration control in a beam of composite material using electromagnetic actuators by means of Linear Quadratic Regulator (LQR) solved by Linear Matrix Inequalities (LMIs). In the search for a good compromise between the energy consumption and the attenuation of vibration, the work also proposes to study the optimization of parameters applied in this control system.

\section{System model}

The beam modeling studied in the present work was presented by [2], its respective global matrix is shown in Eq. (1).

\footnotetext{
* Corresponding author: edsonh@utfpr.edu.br
} 


$$
\left[\mathbf{M}_{g}\right]\left\{\ddot{\mathbf{u}}_{g}\right\}+\left[\mathbf{K}_{u u}\right]\left\{\mathbf{u}_{g}\right\}=\left\{\mathbf{F}_{g}\right\}
$$

where $\left[\mathbf{M}_{g}\right]$ is the global mass matrix, $\left[\mathbf{K}_{u u}\right]$ the global elastic stiffness matrix, $\left[\mathbf{u}_{g}\right]$ the global displacement vector, $\left[\ddot{\mathbf{u}}_{g}\right]$ the second derivative of the displacement, and $\left[\mathbf{F}_{g}\right]$ corresponds to the excitation force. More detail about this model can be obtained in [2].

The system presented by Eq. (1) has a high number of degrees of freedom. Because of this, it was necessary to apply a model reduction technique, in order to guarantee the controllability and observability of the system. The reduced model is obtained by neglecting the states associated with small singular values [3]. The minimal balanced realization of the system is asymptotically stable if the controllability and observability graminians are equal and diagonal [4]. For the present structure, the system was controllable and observable for the first two vibration modes.

\section{Electromagnetic actuator}

The methodology for obtaining the model of an electromagnetic actuator was presented in [6]. Fig. 1 illustrates the model, that consists of a coil wound on a core of ferromagnetic material and the attraction force between the two elements of the ferromagnetic nucleus is represented by the Eq. (1). The parameters of actuator are shown in Table 1

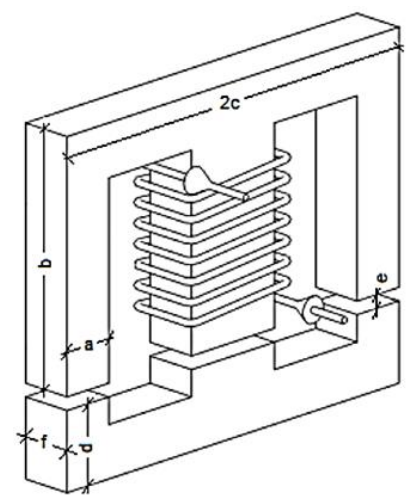

Table 1. Parameters of the coil [9].

\begin{tabular}{|c|c|}
\hline Parameter & Value \\
\hline$\mu_{0}(\mathrm{H} / \mathrm{m})$ & $4 \pi 10^{-7}$ \\
\hline$\mu_{r}$ & 700 \\
\hline$N($ Coil turns $)$ & 250 \\
\hline $\mathrm{a}(\mathrm{mm})$ & 9.5 \\
\hline $\mathrm{b}(\mathrm{mm})$ & 38 \\
\hline $\mathrm{c}(\mathrm{mm})$ & 28.5 \\
\hline $\mathrm{d}(\mathrm{mm})$ & 9.5 \\
\hline $\mathrm{f}(\mathrm{mm})$ & 22.5 \\
\hline $\mathrm{i}_{\mathrm{b}}(\mathrm{A})$ & 0.1 \\
\hline
\end{tabular}

Fig. 1. Electromagnet of the electromagnetic actuator [6].

where $\mu_{r}$ is the relative permeability of the ferromagnetic material of the core and $\mu_{0}$ the vacuum permeability.

Eq. (2) presents the electromagnetic force.

$$
F_{A E M}=\frac{N^{2} i^{2} \mu_{0} a f}{2\left((e \pm \delta)+\frac{b+c+d-2 a}{\mu_{r}}\right)^{2}}
$$

where $i$ the electric current and $\delta$ the variable that is added to the air gap to represent the vibration of the beam. It is worth mentioning that the EMA applies only on attraction force and, thus: the value "+" holds for $\delta>0$; and "-" for $\delta<0$.

Analyzing Eq. (2), it is noted that the amplitude of the electromagnetic force presents a non-linearity. Thus, the actuator model was linearized according to the procedure presented 
in $[7,8]$, where the linearization of the electromagnetic actuator is performed using a methodology similar to that applied to magnetic bearings. The electromagnetic force in the linearized form is presented by Eq. (3).

$$
F_{A E M}=k_{i} i-k_{x} x
$$

where $k_{i}$ is the gain of the actuator, $i$ is the electric current, $k_{x}$ is the rigidity and $x$ is the displacement.

\section{Methodology}

The beam of composite material studied in this work has $306 \mathrm{~mm}$ length, $25.5 \mathrm{~mm}$ width and $1 \mathrm{~mm}$ thickness, and is composed by five layers of graphite/epoxy with $0.2 \mathrm{~mm}$ thickness each layer. The layers have the orientation of $\left[45^{\circ} / 0^{\circ} / 45^{\circ} / 0^{\circ} / 45^{\circ}\right]$ [2], where the orientation of $0^{\circ}$ is parallel to the $x$ axis. The scheme is shown in Fig. 2. The EMA has two parts (see Fig. 1): E and I. The I parts were fixed in the structure and their mass was added in the mass matrix.

For the best possible similarity to the actual behavior, white noises are imposed on the displacement calculations.

In order to obtain a good relation between the energy consumption and the vibration attenuation of the beam, for a better configuration of the system, heuristic optimization methods are used. Fig. 3 shows the schematic form of the controller. This controller was designed using LQR solved by LMIs [5].

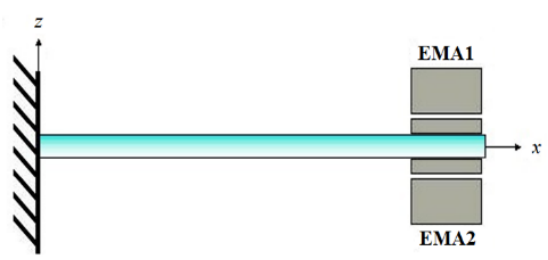

Fig. 2. Positioning of electromagnetic actuators.

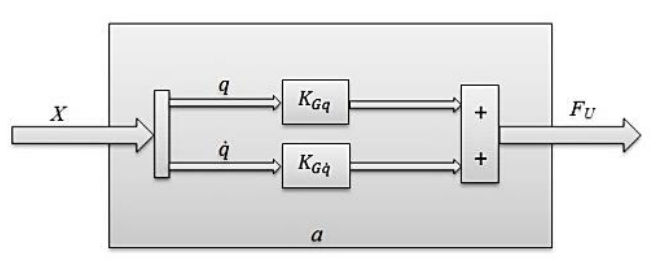

Fig. 3. Controller Schematic [10].

From Fig. 3, the modal displacement component and the modal velocity component were multiplied, respectively, by parameters $c_{1}$ and $c_{2}$. There parameters are the design variables of the optimization problem.

The present optimization problem was composed by two objective functions defined as $F_{1}$ related to the displacement's system and $F_{2}$ related to the electrical current, that is, referring to the control effort. Both functions are presented by Eq. (4).

$$
F_{1}=\min \|\mathbf{x}(t)\|, \quad F_{2}=\min \left\|\mathbf{F}_{u}(t)\right\|=\int I d t
$$

In the present contribution, it was necessary to use multi-objective form, presented by Eq. (5) [9].

$$
F(x)=\left\{\sum_{k=1}^{K}\left[\frac{W_{k}\left\{F_{k}(x)-F_{k}^{\text {best }}(x)\right\}}{F_{k}{ }^{\text {worst }}(x)-F_{k}{ }^{\text {best }}(x)}\right]^{2}\right\}^{1 / 2}
$$

where $x$ is the vector of the design variables, $W_{k}$ is the weight of each $k$-th objective function, $F_{k}(x)$ is the $k$-th objective function, $F_{k}{ }^{\text {best }}(x)$ is the best value of the $k$-th objective function, 
and $F_{k}{ }^{\text {worst }}(x)$ is the worst value of the $k$-th objective function.

Table 2 shows the values of the constants of the commitment function; the combination between $W_{1}$ e $W_{2}$ was done in the form $W_{1}+W_{2}=1.00$. The design space intervals are $0 \leq$ $c_{1} \leq 100$ and $0 \leq c_{2} \leq 100$.

Table 2. Commitment function constants values

\begin{tabular}{|c|c|c|c|c|c|}
\hline $\boldsymbol{F}_{\mathbf{1}}{ }^{\text {best }}$ & $\boldsymbol{F}_{\mathbf{1}}{ }^{\text {worst }}$ & $\boldsymbol{F}_{\mathbf{2}}{ }^{\text {best }}$ & $\boldsymbol{F}_{\mathbf{2}}{ }^{\text {worst }}$ & $\boldsymbol{W}_{\mathbf{1}}$ & $\boldsymbol{W}_{\mathbf{2}}$ \\
\hline 0.0353 & 9.315 & $1.1756 \mathrm{e}-11$ & 2.1628 & 0.01 a 0.99 & 0.99 a 0.01 \\
\hline
\end{tabular}

\section{Results}

In relation to optimization, the optimized values of the design variables $c_{1}$ and $c_{2}$ were obtained as a function of the contribution of $W_{1}$ and $W_{2}$, according to Figs. 4 and 5 .

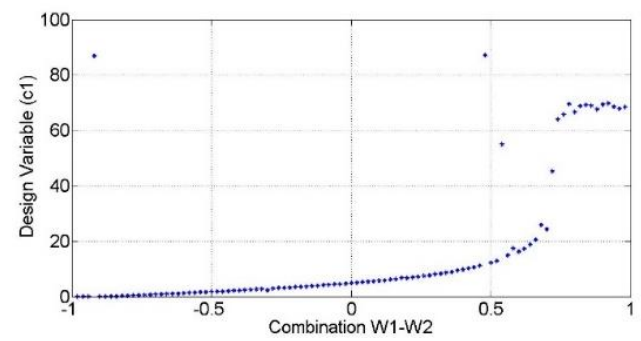

Fig. 4. Design variable $c_{1} x W_{1}-W_{2}$.

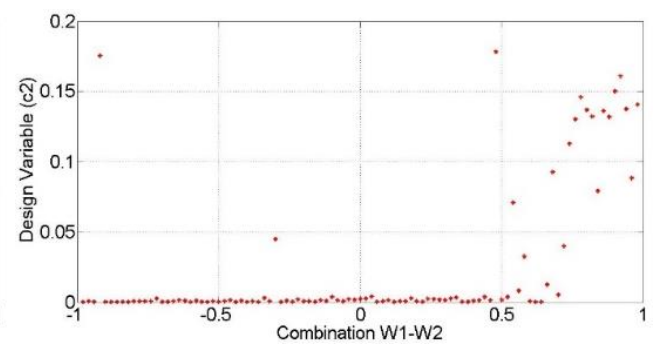

Fig. 5. Design variable $c_{2} x W_{1}-W_{2}$.

It can be seen, from Fig. 4, that the value of the design variable tends to increase with the increase of $W_{1}$, at the same time as $W_{2}$ decreases, that is, it is observed that the design variable $c_{1}$ tends to increase as the influence of the attenuation of the system response increases.

In relation to Fig. 5 , the values of the design variable $c_{2}$ have values close to zero, increasing in the interval 0.5 to 0.99 of the combination $W_{1}-W_{2}$, the interval of the combination in which there is greater influence of $W_{1}$, corresponding to the greater influence of the attenuation of the system response.

The relationship between the objective functions $F_{1}[\mathrm{~m}]$ and $F_{2}[\mathrm{~A}]$ is seen from Fig. 6.

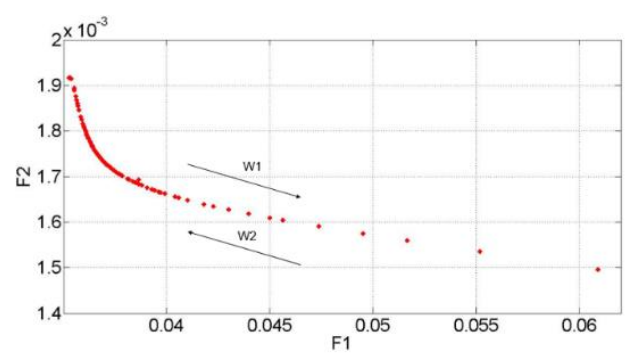

Fig. 6. Comparison $F_{1} x F_{2}$

This result shows, as expected, that the increase in the attenuation of the system response by means of the active control of vibrations through the application of electromagnetic actuators generates an increase in the energy consumption, fact observed by the electric current response $\left(F_{l}\right)$ used by the actuators. In view of this, it is necessary to find a good relation between $W_{1}$ and $W_{2}$, so that it has a good attenuation of vibration of the beam without causing excessive consumption of energy. 
Figs. 7 and 8 present the comparison of the global function between the values of the objective functions $F_{1}$ and $F_{2}$ in function of the variation of $W_{1}$ and $W_{2}$.

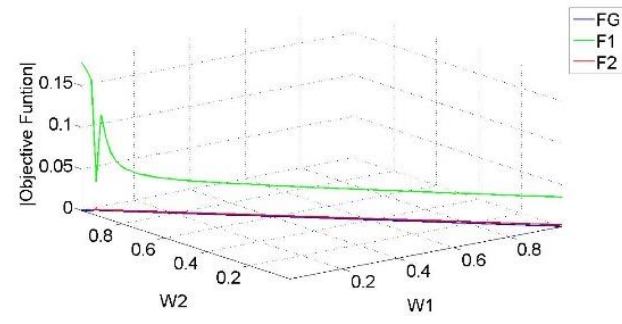

Fig. 7. Comparison of the Global Function between $F_{1}$ and $F_{2}$.

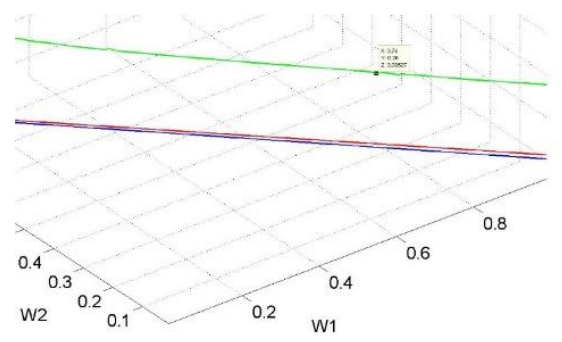

Fig. 8. Approximate image of the Global Function comparison between $F_{1}$ and $F_{2}$.

From the results obtained in Figs. 7 and 8, it was observed that the smallest difference between $F_{1}$ and $F_{2}$ occurs for $W_{1}=0.74$ and $W_{2}=0.26$, so it can be stated that the objective function $F_{1}$ has greater influence on the global function.

For these values of $W_{1}$ and $W_{2}$, the design variables $c_{1}$ and $c_{2}$ are equal to 87.1522 and 0.1783 . The response of the system displacement in the time domain and the electric current of the electromagnetic actuators using the values obtained from the design variables $c_{1}$ and $c_{2}$ are presented in Figs. 9 and 10.

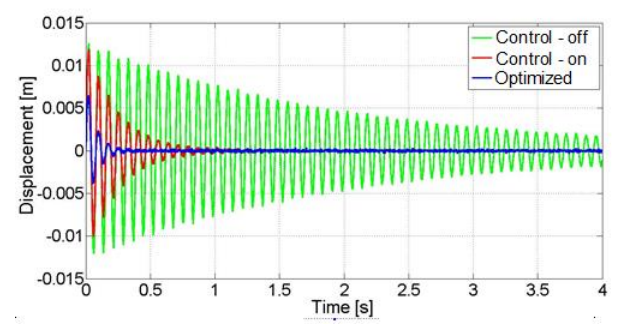

Fig. 9. Response time domain displacement applying optimization.

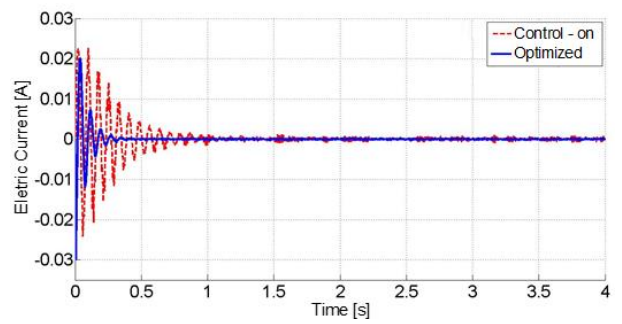

Fig. 10. Electrical current with the application of optimization.

According to Fig. 9, with the objective function $F_{1}$ being the privileged in the global function, it is observed that the vibration attenuation of the system occurs faster, attenuating the system approximately $0.4 \mathrm{~s}$. In the case of Fig. 10, the first oscillation exhibits higher power consumption, but the following oscillations are attenuated according to the displacement response of Fig. 9.

\section{Conclusion}

In general, it can be concluded that the proposed methodology and the tools used presented satisfactory results, making possible its use to improve the performance of active vibration control in beams of composite materials.

The authors gratefully acknowledge the financial support for this research from $\mathrm{CNPq}$ (Process 402581/2016-4), Araucária Foundation and CAPES. 


\section{References}

[1] V.M, Sreehari, D.K. Maiti, Composite Structures, 173, 228-241 (2017)

[2] A.W. Faria. Modelagem por Elementos Finitos de Placas Compostas Dotadas de Sensores e Atuadores Piezolétricos: Implementação Computacional e Avaliação Numérica. Dissertação de Mestrado, Universidade Federal de Uberlândia, Uberlândia MG, 152f. (2006).

[3] L. Meirovitch. Dynamics and Control of Structures. Blacksburg, Department of Engineering Science and Mechanics, 193 p. (1990).

[4] K. Zhou, J. C, Doyle. Essentials of Robust Control, Prentice Hall (1998).

[5] E.H. Koroishi, F.A. Lara-Molina, A.W. Faria, V. Steffen Jr., Journal of Aerospace Technology and Management (Online), 7, 70-80 (2015).

[6] E.H. Koroishi, V. Steffen Jr., Active Vibration Control Using Electromagnetic Actuator: A Simple Model Approach. $10^{a}$ Conferência Brasileira de Dinâmica, Controle e Aplicações (2011).

[7] E. Maslen, Magnetic Bearings, University of Virginia, Department of Mechanical, Aerospace and Nuclear Engineering, Charlottesville, Virginia, 233 p, (2000).

[8] G.N. Vanderplaats. Numerical Optimization Techniques for Engineering Design, Third edition, USA: VR D INC. Colorado Springs (1999).

[9] E.H. Koroishi, F.A. Lara-Molina, A.S. Borges, V. Steffen Jr., Journal of Vibration and Control, 22(17), 3767-3778 (2015)

[10] M.V.F. Oliveira, L.A.A. Rocha, E.H. Koroishi, V. Steffen Jr., VIII Congresso Nacional de Engenharia Mecânica, Uberlândia, p. 1-10 (2014). 